Article

\title{
Benefits of European Climate Policies for Mercury Air Pollution
}

\author{
Peter Rafaj $^{1{ }^{1} *}$, Janusz Cofala ${ }^{1}$, Jeroen Kuenen ${ }^{2}$, Artur Wyrwa ${ }^{3}$ and Janusz Zyśk ${ }^{3}$ \\ 1 International Institute for Applied Systems Analysis (IIASA), A-2361 Laxenburg, Austria; \\ E-Mail: cofala@iiasa.ac.at \\ 2 Climate, Air and Sustainability, TNO, Utrecht 3584 CB, The Netherlands; \\ E-Mail: jeroen.kuenen@tno.nl \\ 3 AGH University of Science and Technology, 30-059 Krakow, Poland; \\ E-Mails: awyrwa@agh.edu.pl (A.W.); jazysk@agh.edu.pl (J.Z.) \\ * Author to whom correspondence should be addressed; E-Mail: rafaj@iiasa.ac.at; \\ Tel.: +43-223-680-7332; Fax: +43-2236-71313.
}

Received: 18 November 2013; in revised form: 18 December 2013 / Accepted: 26 December 2013 / Published: 10 January 2014

\begin{abstract}
This paper presents the methodology and results of impact assessment of renewable energy policies on atmospheric emissions of mercury in Europe. The modeling exercise described here involves an interaction of several models. First, a set of energy scenarios has been developed with the REMix (Renewable Energy Mix) model that simulates different levels of penetration of renewable energies in the European power sector. The energy scenarios were input to the GAINS (Greenhouse Gas and Air Pollution Interactions and Synergies) model, which prepared projections of mercury releases to the atmosphere through 2050, based on the current air pollution control policies in each country. Data on mercury emissions from individual sectors were subsequently disaggregated to a fine spatial resolution using various proxy parameters. Finally, the dispersion of mercury in the atmosphere was computed by the chemistry transport model, implemented to the air quality system, Polyphemus. The simulations provided information on changes in concentrations and depositions of various forms of mercury over Europe. Scenarios that simulate a substantial expansion of renewable energies within the power sector indicate extensive co-benefits for mercury abatement, due to the restructuring of the energy system and changes in the fuel mix. The potential for mercury reductions in Europe depends on the rate of fuel switches and renewable technology deployment, but is also influenced by the stringency and timing of the air quality measures. The overall scope for co-benefits is therefore higher in regions relying on coal combustion as a major energy source.
\end{abstract}


Keywords: mercury emissions; policy scenarios; renewable energies; atmospheric dispersion; co-benefits

\section{Introduction}

During the last few decades, many studies have investigated the environmental impacts of anthropogenic releases of mercury $(\mathrm{Hg})$. The increasing attention on mercury pollution is mainly driven by the growing evidence of its negative impacts on human health and ecosystems [1]. It is well documented that after its deposition, mercury moves through the water chain and can be transformed by aquatic microorganisms into methylmercury $(\mathrm{MeHg})$, a toxic substance bioaccumulated in fish and seafood. MeHg enters the human body with consumed food and is then transported by blood, passes the blood-brain barrier and causes neurotic dysfunctions [2]. Mercury is also capable of passing the placental barrier and has an immense negative impact on the fetus, decreasing the intelligence quotient of the child. In this way, exposure to mercury might affect the development of specific population groups [3].

Evidence of the negative effects of mercury on human health and the environment has led to intergovernmental negotiations on the preparation of a global legally binding instrument on mercury, which was adopted in 2013 [4]. At the European Union (EU) level, the European Commission addressed the concerns about mercury in 2005 in the "Community Strategy Concerning Mercury" aimed at the reduction of the negative impact of mercury and the risks it poses for the environment and human health [5]. In addition, the EU has supported a number of research projects focused on mercury impacts, as well as on different $\mathrm{Hg}$ abatement options.

Combustion of fossil fuels, particularly coal, nowadays represents one of the key sources of anthropogenic emissions of $\mathrm{Hg}$ worldwide. In Europe, coal-based power generation contributes the most to the annual emission loads [1]. Therefore, it is very relevant to examine the extent to which the burden from mercury emissions might be reduced due to strategies aiming at a large-scale replacement of coal and other fossil energies with emerging renewable energy sources. This paper presents the methodology and results of the impact assessment of renewable energy policies for the atmospheric emissions of mercury in Europe. The modeling exercise described here was carried out within the EU's Earth Observation for Monitoring and Assessment of the Environmental Impact of Energy Use (EnerGEO) project and involves the interaction of several models tracing the mercury from its sources to its deposition over the European continent.

In this analysis, emissions of mercury are calculated for each country in Europe, including members of the EU and non-EU states, as well as the European part of the Russian Federation. Emission profiles are computed in five-year steps for the next four decades, and the results are highlighted for the years 2005, 2030 and 2050. Mercury emissions through 2050 from fuel combustion and from industrial processes are computed first for the Baseline scenario, which assumes the continuation of current climate and air-quality policies in each country in Europe. The time evolution of mercury releases and its dispersion in the Baseline is then contrasted with a scenario that assumes a rapid penetration of renewable energy sources in the power generation sector. 
The paper is structured as follows: the next section describes the modeling framework employed in the scenario analysis. Key features of individual models are provided here together with the explanation of the data flow and the inter-linkages between the four modeling tools involved. Section 3 describes the basic input parameters and data used in the models, as well as the main assumptions behind the mercury scenarios. The results of the impact assessment of renewable energy policies are discussed in Section 4, highlighting the major outcomes of computer simulations. Finally, Section 5 presents conclusions and the implications of the analyses.

\section{Modeling Framework}

A comprehensive assessment of policies in favor of the substantial deployment of renewables for the emissions of mercury involves a chain of modeling tools that enable one to develop a set of policy-driven emission scenarios and to quantify the spatial distribution of pressures, i.e., the concentration and deposition of mercury over the European territory. The underlying temporal changes in the fuel mix for power generation in individual European countries have been developed by the REMix (Renewable Energy Mix for Sustainable Electricity Supply in Europe) model. REMix simulates different levels of the penetration of renewable energies in a set of energy scenarios, which constitute an input to the GAINS (Greenhouse Gas and Air Pollution Interactions and Synergies) integrated modeling tool. Projections of power generation by source, combined with information on the evolution of emission control measures, are used in GAINS to compute mercury emissions through 2050.

As illustrated in Figure 1, emission scenarios serve as an input to the TNO_MACC-II (Monitoring Atmospheric Composition and Climate) module that spatially disaggregates mercury emissions from individual sectors for selected time periods into the detailed emission source-categories and distributes $\mathrm{Hg}$ releases to the atmosphere over the grid with a spatial resolution of 7 by $7 \mathrm{~km}$. Thereafter, spatially distributed emission levels are used to model the atmospheric dispersion of mercury with the use of an extended chemistry transport model implemented on the air quality system, Polyphemus. In this step, future changes in the deposition and concentration of $\mathrm{Hg}$ are estimated, while taking into account contributions from natural sources and from mercury sources beyond the European domain. The basic features of the models involved in the assessment are described below.

Figure 1. Data flow between models used for the mercury assessment.

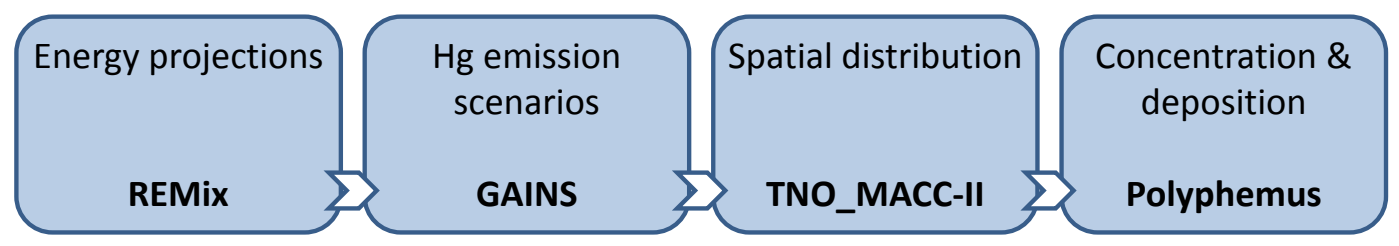

\subsection{REMix}

The REMix model analyses electricity generation potentials in Europe and optimizes renewable electricity generation with demand by calculating the cost-effective electric power supply options. REMix is a combination of a high resolution inventory of renewable electricity generation potentials (solar, wind, geothermal energy, biomass, hydro) and electricity demand data with a linear optimization model 
(50 nodes). It calculates the least cost renewable energy mixes to meet the defined shares of the European electricity demand under given constraints. Resource data with a spatial resolution of $\sim 10 \times 10 \mathrm{~km}$ and a temporal resolution of $1 \mathrm{~h}$ (for solar and wind energy) are input to the inventory [6].

Maps of land use types allowing for sustainable use of resources are generated using a Geographic Information System (GIS). In combination with power plant models, the hourly electricity generation potentials of each source are calculated and provided as input to the linear optimization model. The results of the optimization runs are least-cost electricity generation and transmission structures in Europe under given constraints, provided for each country in Europe and some neighbor countries in the Middle East and North Africa regions. REMix is designed for investigations of the time period between 2005 and 2050 [7].

\subsection{GAINS}

The GAINS model quantifies emission control potentials and costs for exogenous activity projections considering the physical and economic interactions between pollutants. The energy use in all major economic sectors and 20 fuel types is considered. Besides, the model uses projections of activities in energy-intensive industries and in agriculture. More than 2,000 technologies for air pollution mitigation and at least 500 options to control greenhouse gases (GHG) are included. The model computes emissions of major GHGs, air pollutants, as well as mercury. GAINS analyzes the cost-efficiency of policies and measures to meet air quality and GHG targets, covering the period 1990-2050 [8].

In this work, the implementation of $\mathrm{Hg}$ scenarios in GAINS takes advantage of a detailed bottom-up representation of air pollution abatement measures and policies in each country, while being complemented with current legislation on mercury control [9]. Projecting mercury emissions is, however, associated with numerous complexities, since the future $\mathrm{Hg}$ levels result from interactions of a range of determinants, measures and policies that simultaneously address multiple pollutants (e.g., particulates or sulfur) and different environmental objectives (e.g., acidification, exposure to fine particles). It is known that alongside measures dedicated to $\mathrm{Hg}$ capture, most air pollution control devices (APCD) are able to co-control mercury also to a certain extent [10]. Therefore, the amplification effect of multiple controls is considered in the computation algorithm: the application rate of $\mathrm{Hg}$ removing $\mathrm{APCDs}$ is derived as an overlap of rates ( $\mathrm{x}$ ) for individual technologies controlling different pollutants. Figure 2 provides a schematic example of the GAINS multi-pollutant framework, whereby an overlap of two technologies — one abating sulfur dioxide $\left(\mathrm{SO}_{2}\right)$ and the second abating particulate matter (PM) - is computed as a minimum of application rates if both technologies are used in parallel in a given sector, e.g., a coal-fired power plant. Finally, mercury emissions in GAINS are computed at the level of the three most important forms: elemental $\left(\mathrm{Hg}^{0}\right)$, reactive $\left(\mathrm{Hg}^{\mathrm{II}}\right)$ and particulate-bound $\left(\mathrm{Hg}_{\mathrm{P}}\right)$ mercury. The development of shares of $\mathrm{Hg}$ species in future emissions is particularly relevant, due to the differences in their lifetime and atmospheric transport. Speciated emissions for individual countries provide inputs for dispersion modeling tools, such that $\mathrm{Hg}$ concentration and deposition levels can be calculated. 
Figure 2. Illustration of a multi-pollutant technology approach for $\mathrm{Hg}$ control in GAINS.

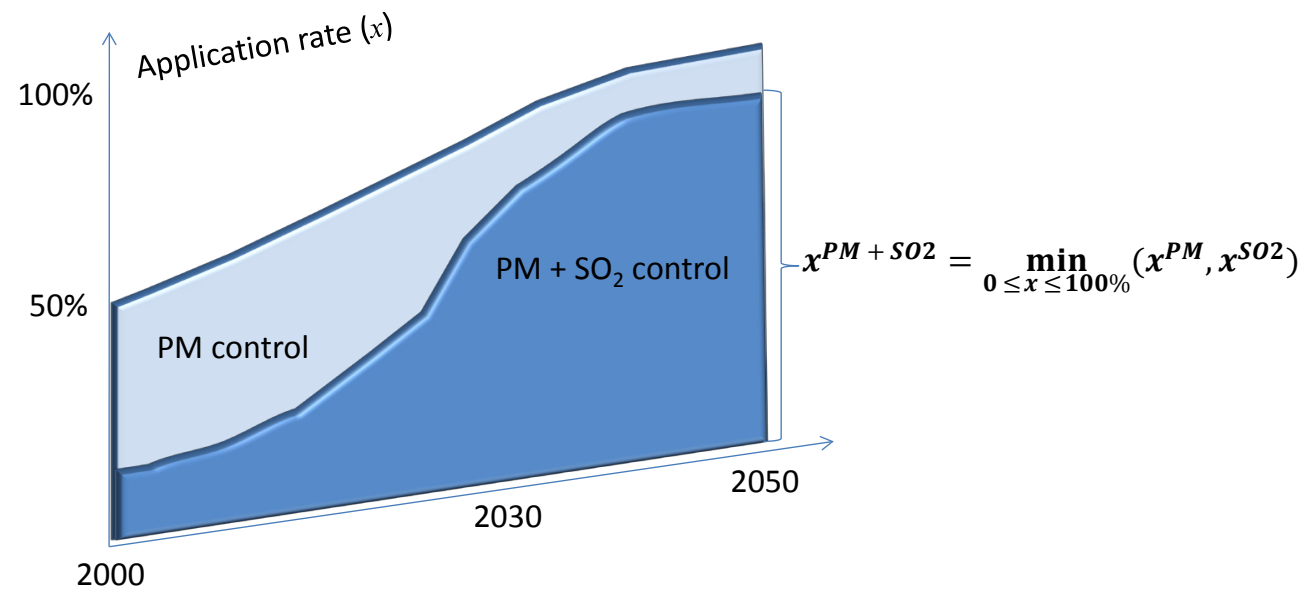

\subsection{System for Spatial Distribution of Emissions}

For the assessment of concentrations and the deposition of mercury, a correct spatial distribution of emissions over the grid is essential. The gridding procedure, which has been developed within the TNO_MACC-II inventory [11], is used. The spatial distribution system first aggregates the emissions by GAINS activity and sector to a set of 75 emission categories, which are distributed using different proxy parameters, distinguishing area and point sources. For point sources, the system utilizes its own database of point sources, but also The European Pollutant Release and Transfer Register (E-PRTR) is used as a data source for selected countries and pollutants. However, for mercury, this source is not used, because emission estimates from individual plants are not considered to be accurate and consistent enough. Our own database on point sources is set up using, among others, information from commercial databases, such as the Platts database for power plants [12], where capacity is assumed to be proportional to emission strength. The point source database is used as a fractional distribution map for distributing aggregated emissions from the GAINS model, i.e., the point source emissions are first normalized, adding up to $100 \%$ for each country, and then, all percentages are multiplied with the emission total for that country for a given pollutant, sector and year. Area sources are distributed using proxy parameters, at a spatial resolution of $1 / 8^{\circ} \times 1 / 16^{\circ}$ longitude-latitude (approximately $7 \times 7 \mathrm{~km}$ ). The proxy parameters used include, e.g., population and arable land, but also road, rail and shipping networks. The proxy parameters selected for the distribution of mercury emissions are similar to those selected for the other pollutants. For more information and a complete overview of the spatial distribution system, we refer to Kuenen et al. [11]. A more extensive description of the spatial distribution methodology can also be found in van der Gon et al. [13], which describes an earlier version of the spatially distributed inventory for the year 2005. The calculations are performed using a Structured Query Language (SQL) server platform to reduce computation time. The resulting gridded emissions are aggregated to the 13 source categories to reduce the file size of the output files. The spatial distribution system has been developed for the year 2005. For future years, due to the lack of reliable information, the spatial distribution key is assumed not to change, i.e., reductions by sector are applied evenly to all grid cells within each of the 75 emission categories. 


\subsection{Polyphemus}

Polyphemus is an air quality modeling system, which was used in this study to model atmospheric dispersion of the main mercury forms $\left(\mathrm{Hg}^{0}, \mathrm{Hg}^{\mathrm{II}}, \mathrm{Hg}_{\mathrm{p}}\right)$ and species $(\mathrm{HgO}, \mathrm{HgCl}$, etc. $)$ over Europe [14]. Its main element is an Eulerian chemistry-transport-model, Polair3D, used for both gaseous and aerosol species. Polair3D tracks multiphase chemistry: (i) gas, (ii) water and (iii) aerosols. Polyphemus is also composed of a library of physical parameterizations, called AtmoData, and a set of programs using AtmoData designed to generate data required by Polair3D, e.g., deposition velocities, vertical diffusion coefficients, emissions, etc. Polyphemus was equipped with a new chemical scheme dedicated to the atmospheric chemistry of mercury, which takes into account the main reactions and processes in the gaseous, aqueous and particulate phases, as presented in Figure 3. This scheme is an upgraded version of the one introduced in Roustan et al. [15]. Its main developments are related to the reactions of mercury with bromine. Additionally, particulate mercury is distributed among 10 different size sections (diameter between 0.01 to $10 \mu \mathrm{m}$ ).

Figure 3. The chemical model for mercury implemented in Polyphemus. Gaseous and aqueous $\mathrm{Hg}$ phases are marked by white and blue, respectively. The line arrows show possible transformations of mercury, and the dashed arrows show additional species used in the model that react with mercury.

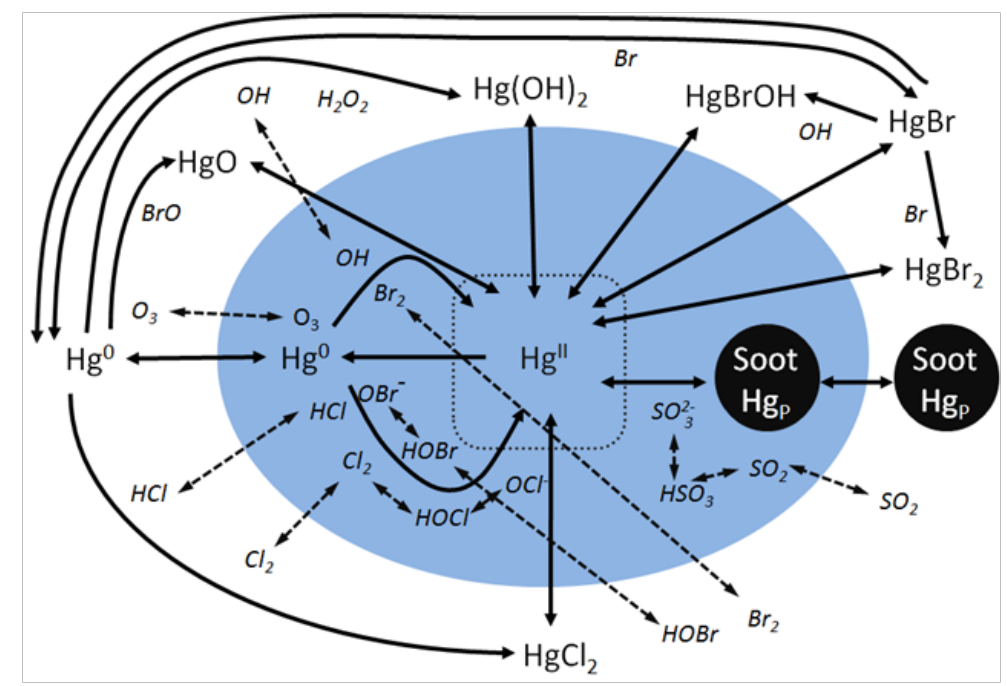

The dry deposition velocity for gaseous compounds is calculated based on the model and parameters presented in Zhang et al. [16,17], whereas for particulate species it is calculated based on [18]. The wet deposition is split between in-cloud and below cloud scavenging with the use of parameterization provided by Binkowski et al. [19], Sportisse et al. [20], and Seinfeld et al. [21]. The validation of the model can be found in Zyśk et al. [22,23]. The modeling domain consists of $120 \times 140$ cells with a horizontal resolution of $0.5^{\circ} \times 0.25^{\circ}$ (along longitude and latitude, respectively). Ten vertical levels are used with the following limits (in meters above the surface): zero; 70; 150; 300; 500; 750; 1,000; 2,000; 3,000; 5,000. The ECMWF (European Centre for Medium-Range Weather Forecasts) data for meteorological parameters and EMEP (European Monitoring and Evaluation Programme) data for natural emissions and reemissions are used. The initial and boundary conditions were set to $0.0012 \mathrm{ppt}$ for $\mathrm{HgO}, \mathrm{Hg}(\mathrm{OH})_{2}, \mathrm{HgCl}_{2}, \mathrm{Hg}_{\mathrm{P}}$ and $0.185 \mathrm{ppt}$ for $\mathrm{Hg}^{0}$. 


\section{Assumptions for Mercury Scenarios}

Two Hg emission scenarios are presented in this paper: (1) the Baseline scenario (BAS), which assumes the development of the European energy system with no measures to control the emissions of GHGs and to deploy renewable electricity sources going beyond the current policies; and (2) the Maximum Renewable Power (MAX) scenario that assumes the decarbonization of the European energy system, including the highest possible electricity (ELE) generation from renewables by 2050. Both scenarios imply a full implementation of recent national legislation on air quality (i.e., policies that were in force or in the final stage of legislative processes as of mid-2012) by 2030, but not strengthening it further between 2030 and 2050.

\subsection{Combustion Sources of Mercury}

Figure 4 depicts the developments of primary energy demand in the Baseline and the Maximum Renewable Power scenarios. The Baseline assumes an increase of the energy use in Europe by about 7\% until 2050, which is a combined effect of a decrease in the EU Member States by $6 \%$ and an increase in the rest of Europe by 38\%. Even in the Baseline, the share of fossil fuels decreases from $81 \%$ in 2005 to $67 \%$ by 2050 . The share of biomass and other renewable energy increases from $6 \%$ to $16 \%$. The Maximum Renewable Power scenario results in a much lower energy demand in 2050 relative to the Baseline. In the EU countries, this demand decreases by more than $30 \%$, and the aggregated reduction for other Europe countries is about $40 \%$. This is a combined effect of a decrease of the demand for final energy, due to a faster implementation of energy efficiency measures and due to the higher share of non-combustion renewable energy sources in power generation.

Figure 4. Demand for primary energy in EU-27 and non-EU regions in the Baseline and the Maximum Renewable Power scenarios. Source: REMix and GAINS.

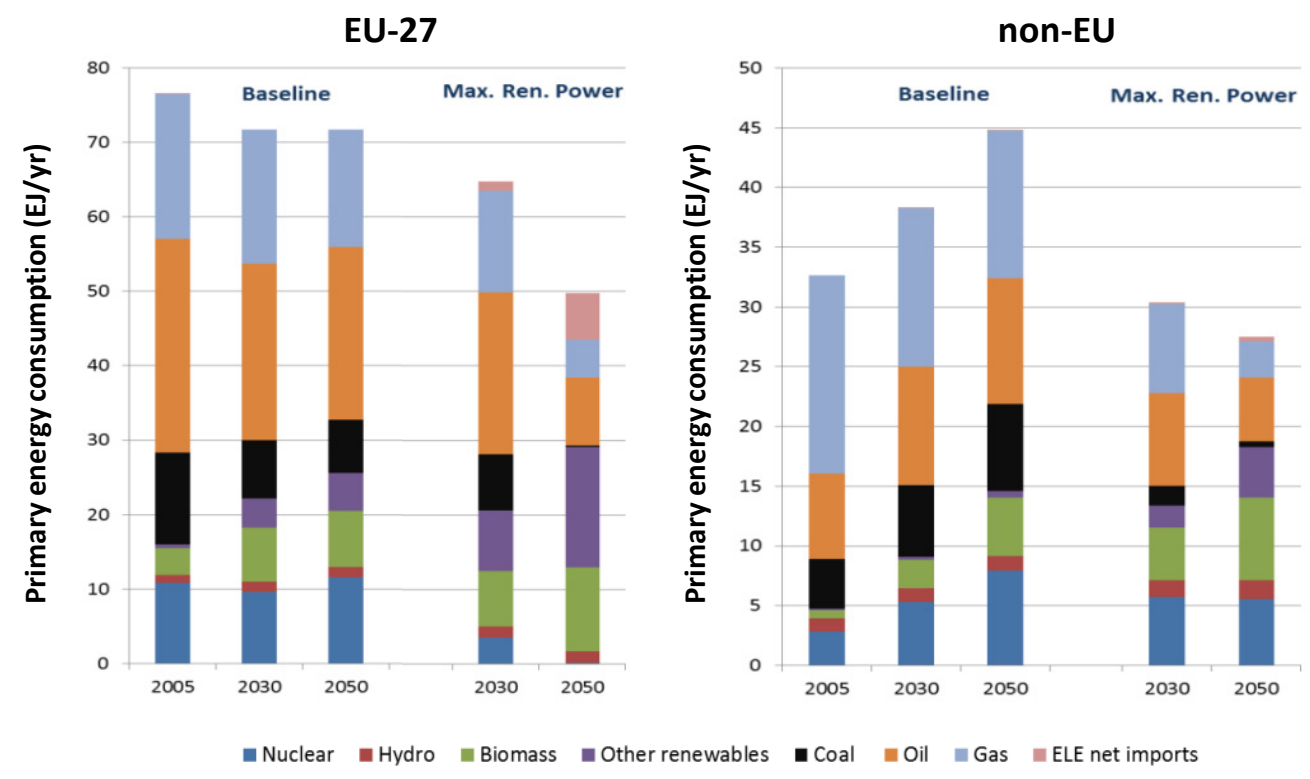

The share of renewables in the primary energy consumption, as projected by the REMix model, increases up to 2050 in the EU countries to $58 \%$ and to $46 \%$ in the non-EU countries. In addition, more than one fourth of electricity demand is met through imports of solar-based electricity from Africa in 
the MAX scenario by 2050. For the EU-27, the contribution of solar-power imports to the power generation fuel mix reaches $34 \%$. In this way, the electricity supply for the EU-27 is practically carbon free; only less than $5 \%$ originates from coal and gas.

\subsection{Non-Combustion Sources of Mercury}

Non-combustion $\mathrm{Hg}$ sources comprise industrial processes, such as refineries, iron and steel production, non-ferrous metals smelting, the production of non-metallic minerals and chemical products. Projections of activities in industrial processes in the EU-27 are based on inputs from the reference- and low-carbon-scenarios reported by CEC [24]. Estimates for non-EU countries rely on the activities provided by Russ et al. [25] or they are derived from trends in macroeconomic drivers (e.g., gross domestic product, value added in individual sectors). The growth in industrial production relative to the present is significantly faster in the non-EU region, as compared to the EU-27. Climate policies, however, result in reduced growth rates for industrial processes in all European states, due to assumptions on higher energy prices, rapid implementation of efficiency measures and overall economic restructuring.

Additional mercury sources of air emissions covered in GAINS include chlorine and gold production, waste incineration and dental-mercury emissions (from cremations). In recent years, the mercury cell capacity in chloralkali plants has been gradually reduced through closures or conversion to non-Hg technologies [26]. This process was driven by environmental regulations and cost reasons. Therefore, we assume that chloralkali facilities using mercury will be phased out in Europe by 2030. Industrial gold mining occurs in a number of European countries. Activity projections for the gold mining sector are derived from the extrapolation of recently observed trends up to 2030 [27], and the production is kept constant thereafter. Estimates of $\mathrm{Hg}$ emissions from dental sources are based on the future population growth, annual mortality rates and from the recent trends in the share of cremations [28]. There are few sectors and potential Hg sources in Europe (e.g., intentional mercury use in batteries, lamps or other devices) not modeled explicitly, due to high uncertainties and data scarcity. This study assumes that the activities in Hg-specific sectors listed in this paragraph are not affected by the climate policies.

\subsection{Emission Factors and Control Options for Mercury}

Uncontrolled emission factors are derived from literature sources on mercury contents in combustible fuels or wastes and from estimates on $\mathrm{Hg}$ impurities in raw materials used in production processes. Emissions of mercury in flue gases are estimated in GAINS for each of the major $\mathrm{Hg}$ forms by taking into account the removal efficiency and application rate of a wide range of control measures. The model also takes into account the retention of mercury in fly ash. Changes in the mercury speciation in flue gases due to pollution controls are reflected by using the inlet and outlet composition factors. The main parameters applied for the calculation of $\mathrm{Hg}$ emissions in Europe are reported in Table 1.

There are two types of control measures for mercury considered in GAINS. The first set of measures includes "conventional" APCDs, which reduce mercury as a side effect of their operation. As discussed in Section 2.2, the removal efficiency of APCDs for $\mathrm{Hg}$ is in most cases reinforced if they are adopted simultaneously. The second set contains technologies directly dedicated to the capture of mercury. The 
Hg-specific primary abatement measures, such as sorbent injection, are associated with the model with relevant sectors, e.g., waste incineration, crematories or chloralkali production. The implementation rates of air pollution and $\mathrm{Hg}$ control strategies are based on recent national legislation, i.e., policies that were in force or in the final stage of the legislative process as of mid-2012 [29].

Table 1. Summary of the parameters and characteristics of control options used for Hg calculation in Europe.

\begin{tabular}{|c|c|c|c|c|c|}
\hline \multicolumn{2}{|c|}{ Activity Types } & $\begin{array}{c}\text { Emission Factors }^{2} \\
\text { (grams Hg/activity) }\end{array}$ & $\begin{array}{c}\text { Speciation-Inlet (\%) } \\
\mathrm{Hg}^{0}-\mathrm{HG} G^{I I}-\mathrm{Hg}_{P}\end{array}$ & Control Measures $^{3}$ & $\begin{array}{c}\text { Removal } \\
\text { Efficiency (\%) } \\
\text { Hg }^{0}-H G^{I}-H g_{P}\end{array}$ \\
\hline \multirow{8}{*}{ Combustion } & & & & CYC & $0-0-70$ \\
\hline & Hard coal $^{1}$ & $0.001-0.009(\mathrm{~g} / \mathrm{PJ})$ & $55-35-10$ & WSCR & $10-40-85$ \\
\hline & Lignite $^{1}$ & $0.007-0.048(\mathrm{~g} / \mathrm{PJ})$ & $60-30-10$ & ESP & $15-30-95$ \\
\hline & Biomass & $0.001(\mathrm{~g} / \mathrm{PJ})$ & $50-40-10$ & $\mathrm{ESP}+\mathrm{FGD}+\mathrm{SCR}$ & $35-80-99$ \\
\hline & Oil products & $0.0001-0.001(\mathrm{~g} / \mathrm{PJ})$ & $50-40-10$ & $\mathrm{FF}$ & $45-60-99$ \\
\hline & Waste & $0.6-1(\mathrm{~g} / \mathrm{t})$ & $20-60-20$ & $\mathrm{FF}+\mathrm{FGD}+\mathrm{SCR}$ & $60-95-99$ \\
\hline & Cremation & $2.5(\mathrm{~g} /$ corpse $)$ & $80-15-5$ & $\mathrm{FF}+\mathrm{FGD}+\mathrm{SCR}+\mathrm{SI}$ & $95-99-99$ \\
\hline & & & & GP & $70-70-70$ \\
\hline \multirow{4}{*}{ Metallurgy } & Iron and steel & $0.04(\mathrm{~g} / \mathrm{t})$ & $80-15-5$ & CYC & $0-0-70$ \\
\hline & Non-ferrous metals & $0.01-5(\mathrm{~g} / \mathrm{t})$ & $80-15-5$ & ESP & $15-30-95$ \\
\hline & & & & $\mathrm{ESP}+\mathrm{FGD}+\mathrm{SCR}$ & $30-50-99$ \\
\hline & Industrial gold mining & $25(\mathrm{~g} / \mathrm{kg})$ & $80-15-5$ & $\mathrm{FF}+\mathrm{FGD}+\mathrm{SI}$ & $95-99-99$ \\
\hline \multirow{5}{*}{ Processes } & Oil refineries & $0.001-0.02(\mathrm{~g} / \mathrm{t})$ & $80-15-5$ & CYC & $0-0-70$ \\
\hline & Cement and lime & $0.035(\mathrm{~g} / \mathrm{t})$ & $80-15-5$ & ESP & $15-30-95$ \\
\hline & Other bulk products & $0.001(\mathrm{~g} / \mathrm{t})$ & $80-15-5$ & $\mathrm{ESP}+\mathrm{FGD}+\mathrm{SCR}$ & $30-50-99$ \\
\hline & \multirow{2}{*}{ Chloralkali production } & \multirow{2}{*}{$2.5(\mathrm{~g} / \mathrm{t} \mathrm{Cl})$} & \multirow{2}{*}{$70-30-0$} & GP & $30-30-0$ \\
\hline & & & & SI & $95-99-0$ \\
\hline
\end{tabular}

Notes: ${ }^{1} \mathrm{Hg}$ retention in ash $1-17 \% ;{ }^{2}$ ranges reflect regional differences in $\mathrm{Hg}$ contents in coal and other fuels (considering calorific values and import/export patterns). ${ }^{3}$ Acronyms: CYC, cyclone; ESP, electrostatic precipitator; FF, fabric filter; FGD, flue gas desulfurization; GP, good practices; SCR, selective catalytic reduction; SI, sorbent injection; WSCR, wet scrubber. Further details and data sources provided in Rafaj et al. [9].

\section{Simulation Results}

In 2005, the European emissions of mercury from anthropogenic sources totaled 145 tones (this value lies within a range for respective regions estimated by UNEP [1]), and the future trend up to 2050 is fairly flat. Although the $\mathrm{Hg}$ emissions in Europe would have been 35\% to $45 \%$ higher without the co-control effects of technologies abating other air pollutants, APCDs assumed in the Baseline scenario are insufficient to prevent future emission growth in some of the non-EU countries. Stringent decarbonization policies, as defined in the Maximum Renewable Power scenario, induce overall reductions in $\mathrm{Hg}$ emissions of nearly 45 tons in 2050 relative to the Baseline. Cumulatively, the co-benefits from low carbon policies, including a rapid deployment of renewable power sources, are quantified at 1.2 kilotons of avoided mercury emissions in the period 2020-2050 (see the country and sectorial inventory, Table S1 and Table S2 in the Supplementary Material). Figure 5 (left panel) 
illustrates the share of remaining emissions by sector in the MAX scenario and indicates the size of $\mathrm{Hg}$ avoided due to climate measures. The largest fraction (63\%) of emission cuts brought about in the MAX scenario is attributed to the deployment of renewables in the power sector, while the remainder of the reductions originates from changes in industrial activities. Detailed scenario-analysis suggests an increase in $\mathrm{Hg}$ emissions over the Baseline from biomass and waste combusting facilities, because of a larger consumption of these fuels for energy purposes.

As is shown in the right panel of Figure 5, emission reductions achieved under the low-carbon policies are very country-specific and depend on a number of factors, e.g., the amount and quality of the coal used for combustion in power and industry sectors in the Baseline, the timing of the adoption of air pollution controls, the characteristics of abatement technologies used in individual countries, etc. In general, countries relying on coal as the dominant energy source (for example, Poland or Turkey) are likely to cut their $\mathrm{Hg}$ emissions deeper when compared to regions with a more diversified fuel mix.

Figure 5. Maximum Renewable Power scenario: mercury emissions in Europe by sector (left panel) and reductions for selected regions (right panel).
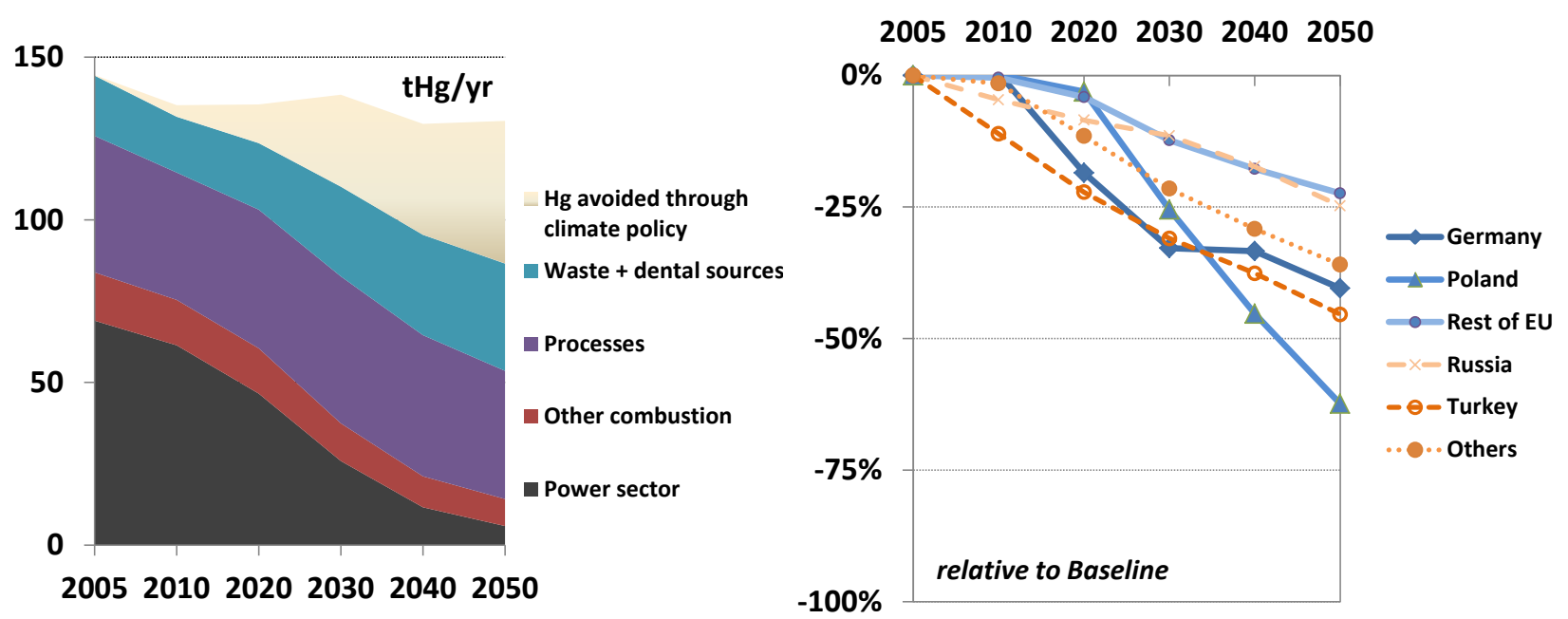

The emissions of mercury from the power sector already decline in the EU-27 without climate policies (Figure 6). Baseline emissions in 2030 are halved relative to today's levels, and by 2050, they decrease by a factor of four. On the contrary, $\mathrm{Hg}$ releases from electricity generation in the non-EU region are twice as high as in the year 2005. The dominant source of mercury from power plants in both regions is the combustion of coal. The contribution of liquid fuels to $\mathrm{Hg}$ emissions is negligible. A rapid elimination of coal from the fuel mix, as in the MAX scenario, causes substantial mercury reductions. In EU-27, climate strategies prevent up to 12 tons of $\mathrm{Hg}$ from being emitted in 2050. This effect is even more pronounced in the non-EU region, where the switch from coal to renewables causes a $\mathrm{Hg}$ decline by $80 \%$ below the emissions in 2005 . One of the fuels that replaces coal is biomass. Although the mercury content of biomass is small by comparison to coal or lignite, the growth in biomass (and partly waste) combustion results in higher $\mathrm{Hg}$ emissions from this source. The corresponding increase in 2050 over the Baseline is $80 \%$ for the EU-27 and 15\% for the non-EU countries.

The final step in the scenario assessment of mercury involves the dispersion modeling of spatially-distributed emissions with the use of a chemistry transport model implemented on the Polyphemus platform. First, the results are presented in Figure 7 for the year 2005 in the form of maps 
showing dry and wet deposition of mercury over the European domain. The majority of the modeled area remains below the deposition levels of $50 \mathrm{~g} \cdot \mathrm{km}^{-2} \cdot \mathrm{yr}^{-1}$; nevertheless, there are regions with elevated deposition reaching $80 \mathrm{~g} \cdot \mathrm{km}^{-2} \cdot \mathrm{yr}^{-1}$ (Poland, NW Germany and Northern Spain). The observed differences in total mercury deposition in Europe are mainly due to the differences in the deposition of reactive gaseous mercury $\left(\mathrm{Hg}^{\mathrm{II}}\right)$ and mercury bounded in aerosols $\left(\mathrm{Hg}_{\mathrm{p}}\right)$. Reactive gaseous mercury $\left(\mathrm{Hg}^{\mathrm{II}}\right)$ and mercury bounded in aerosols $\left(\mathrm{Hg}_{\mathrm{p}}\right)$ are good indicators of coal combustion, because these forms are dispersed in the atmosphere locally, and their deposition strongly depends on local sources. This also explains the spatial feature of the deposition difference, which implies the highest $\mathrm{Hg}$ abatement potential in areas where coal is used at present.

Figure 6. Mercury emissions from the power sector by fuel in the EU-27 and non-EU countries.
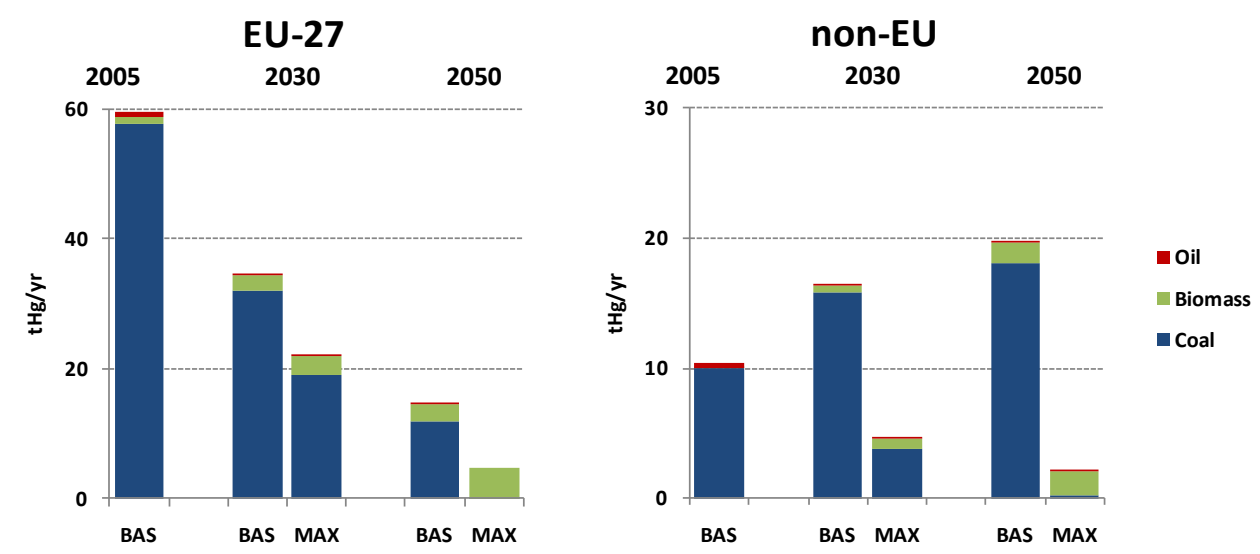

Figure 7. (Left panel) Dry deposition of mercury over Europe in 2005. (Right panel) Wet deposition of mercury over Europe in 2005. Units: $\mathrm{g} \cdot \mathrm{km}^{-2} \cdot \mathrm{yr}^{-1}$.
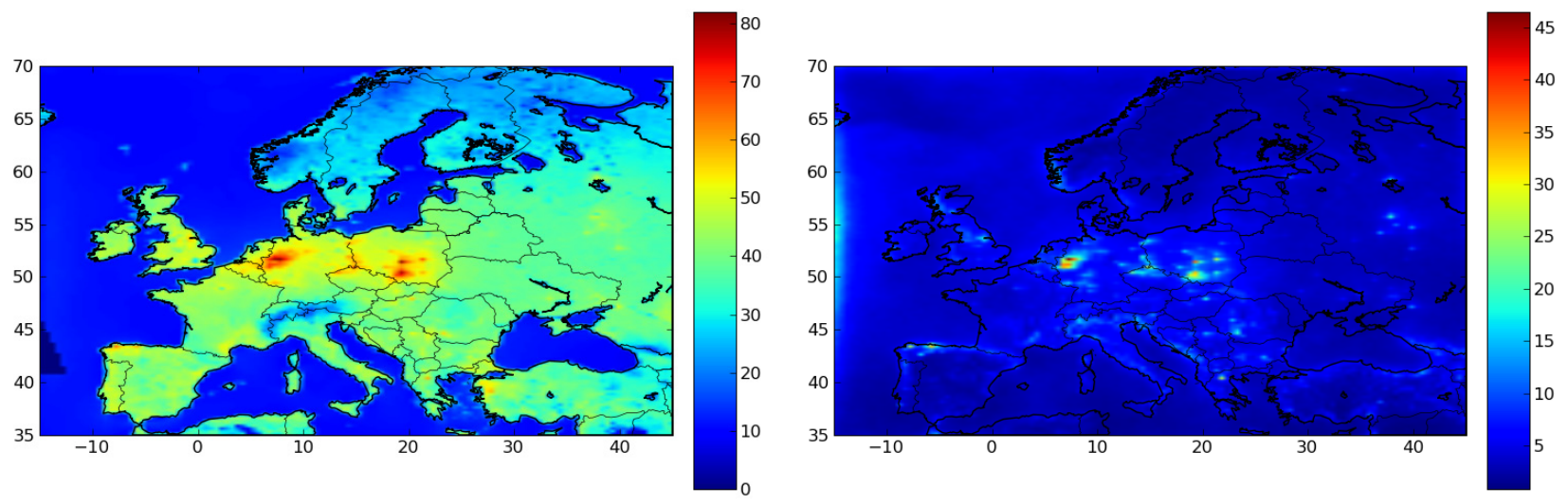

As shown in Figure 8 (left panel), there are significant spatial differences expected in overall $\mathrm{Hg}$ deposition (wet and dry) in the Baseline between the years 2005 and 2030. In some regions (e.g., The Czech Republic, Germany, Poland), the deposition decreases more than $10 \mathrm{~g} \cdot \mathrm{km}^{-2} \cdot \mathrm{yr}^{-1}$, whereas an increase is projected in other parts of Europe (Italy, Russia and Turkey). The performed simulations provide insights about future changes in concentrations and depositions of various forms of mercury over Europe as a consequence of policies favoring renewable power sources. The right panel of 
Figure 8 suggests that fuel mix changes assumed in the MAX scenario in 2030 might induce a reduction in the $\mathrm{Hg}$ deposition of $20 \mathrm{~g} \cdot \mathrm{km}^{-2} \cdot \mathrm{yr}^{-1}$ in some areas (Germany, Poland and Turkey).

Finally, computer simulations allow for the quantification of shares of $\mathrm{Hg}$ from natural sources, as well as global and regional anthropogenic sources of $\mathrm{Hg}$ deposition over the European territory. Taking Poland as an example, the local anthropogenic sources contributed 30\% to the total $\mathrm{Hg}$ deposition in 2005. The contribution of anthropogenic emissions originating in other parts of Europe to the total deposition in Poland is estimated at about $5 \%$. The reminder $(60 \%-70 \%$, depending on the period of the year) is attributed to anthropogenic emissions from non-European sources, natural emissions and re-emissions [22].

Figure 8. (Left panel) The change in the Hg deposition over Europe between 2005 and 2030 for the Baseline scenario. Positive numbers indicate an increase and negative ones a reduction in the deposition levels. (Right panel) The difference in the $\mathrm{Hg}$ deposition over Europe in 2030 between the Baseline and the Maximum Renewable Power scenarios. Units: $\mathrm{g} \cdot \mathrm{km}^{-2} \cdot \mathrm{yr}^{-1}$.
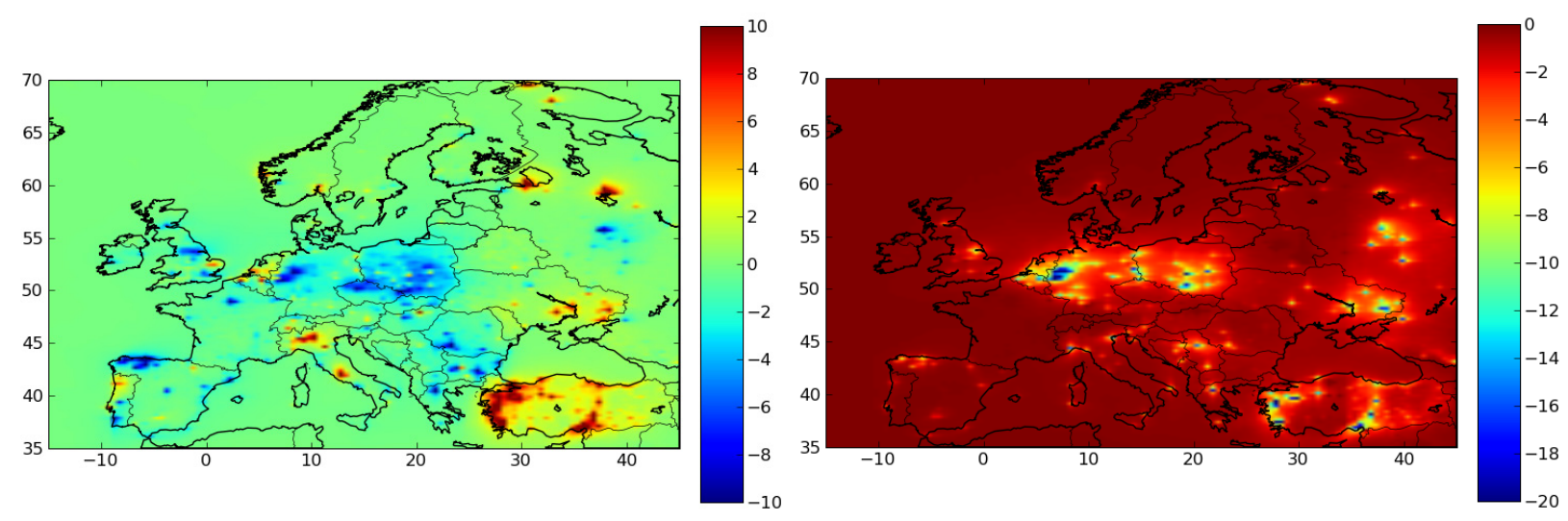

\section{Conclusions}

The change in mercury emissions caused by switching from fossil fuels to carbon-free energy sources is an important indicator for the assessment of renewable energy policies. The results of the comprehensive modeling exercise presented in this paper provide an estimate of the effectiveness of the decarbonization of the energy sector and, in particular, of power generation for mercury mitigation. The most important findings and conclusions from this analysis are:

- Current emissions of mercury in Europe are about 145 tons per year and are likely to remain at the same level under the baseline conditions. Coal and lignite combustion for power generation are the largest sources, contributing $60 \%$ to the total.

- The operation of air pollution control devices required by the current standards to control air quality (dust, sulfur and nitrogen oxides emissions) reduces the emissions of mercury by about $35 \%$. However, without additional climate measures, pollution controls will have to be significantly tightened in some non-EU countries to reverse the growing trend in $\mathrm{Hg}$ emissions by mid-century.

- Decarbonization of the energy system and, in particular, renewable electricity deployment brings extensive co-benefits for mercury abatement. European $\mathrm{Hg}$ emissions under the 
low-carbon policies decrease by one third in 2050 relative to the Baseline, whereby about two thirds of that reduction is achieved in power sector.

- The potential for mercury reduction in each country through implementing renewable electricity generation options depends on the rate of fuel switches and renewable technology deployment, but is also influenced by the stringency and timing of the air quality measures. The overall scope for co-benefits is therefore higher in regions with a high share of coal use and with less stringent policies to control air quality.

- While a rapid decrease in mercury releases from coal-fired power plants under low-carbon strategies is expected, the $\mathrm{Hg}$ emissions from biomass and waste burning might slightly increase, due to a larger amount of these fuels utilized in the energy sector.

- Local and regional sources constitute only a fraction of mercury loads deposited over Europe. Due to the long range transport of elemental mercury in the atmosphere, effective strategies for mitigating mercury contamination require global coordinated actions.

\section{Acknowledgments}

Research presented here has been carried out within the EnerGEO project (www.energeo-project.eu), funded by the European Community's Seventh Framework Programme.

\section{Author Contributions}

All authors designed the modeling experiments, analyzed the data, and contributed extensively to the work presented in this paper. P.R. and J.C. developed the Hg-emission scenarios. J.K. performed the spatial distribution of emissions. A.W. and J.Z. carried out the dispersion modeling of mercury. P.R. prepared the manuscript. All authors discussed the results and implications and commented on the manuscript at all stages.

\section{Conflicts of Interest}

The authors declare no conflict of interest.

\section{References and Notes}

1. UNEP. Global Mercury Assessment 2013: Sources, Emissions, Releases and Environmental Transport; United Nations Environment Programme (UNEP) Chemicals Branch: Geneva, Switzerland, 2013.

2. Munthe, J.; Bodaly, R.A. (Drew); Branfireun, B.A.; Driscoll, C.T.; Gilmour, C.C.; Harris, R.; Horvat, M.; Lucotte, M.; Malm, O. Recovery of Mercury-Contaminated Fisheries. AMBIO 2007, $36,33-44$.

3. Rice, D.C. Overview of modifiers of methylmercury neurotoxicity: Chemicals, nutrients, and the social environment. NeuroToxicology 2008, 29, 761-766.

4. UNEP. Report of the Governing Council, Twenty-Fifth Session (16-20 February 2009), General Assembly, Supplement No. 25; United Nations Environment Programme: New York, NY, USA, 2009. 
5. CEC. Communication "Community Strategy concerning Mercury”; Commission of the European Communities: Brussels, Belgium, 2005.

6. Nitsch, J.; Pregger, T.; Scholz, Y.; Naegler, T.; Heide, D.; Tena, D.L.; Trieb, F.; Nienhaus, K.; Gerhardt, N.; Oehsen, A.; et al. Long-Term Scenarios and Strategies for the Deployment of Renewable Energies in Germany in View of European and Global Developments; DLR: Stuttgart, Germany, 2012.

7. Scholz, Y. Renewable Energy Based Electricity Supply at Low Costs-Development of the REMix Model and Application for Europe; Universität Stuttgart: Stuttgart, Germany, 2012.

8. Amann, M.; Bertok, I.; Borken-Kleefeld, J.; Cofala, J.; Heyes, C.; Höglund-Isaksson, L.; Klimont, Z.; Nguyen, B.; Posch, M.; Rafaj, P.; et al. Cost-effective control of air quality and greenhouse gases in Europe: modeling and policy applications. Environ. Model. Softw. 2011, 26, 1489-1501.

9. Rafaj, P.; Bertok, I.; Cofala, J.; Schöpp, W. Scenarios of global mercury emissions from anthropogenic sources. Atmos. Environ. 2013, 79, 472-479.

10. Pacyna, J.M.; Sundseth, K.; Pacyna, E.G.; Jozewicz, W.; Munthe, J.; Belhaj, M.; Aström, S. An assessment of costs and benefits associated with mercury emission reductions from major anthropogenic sources. J. Air Waste Manag. Assoc. 2010, 60, 302-315.

11. Kuenen, J.J.P.; Visschedijk, A.J.H.; Jozwicka, M.; van der Gon, H.D. A multi-year consistent high-resolution European emission inventory for air quality modelling. Atmos. Chem. Phys. 2013, in press.

12. Platts. World Electric Power Plants Database; Global Market Data and Price Assessments; Platts, UDI Products Group: Washington, DC, USA, 2013.

13. Van der Gon, H.D.; Visschedijk, A.; van de Brugh, H.; Dröge, R. A High Resolution European Emission Data Base for the Year 2005. A Contribution to UBA-Projekt PAREST: Particle Reduction Strategies; TNO Report TNO-034-UT-2010-01895_RPT-ML; TNO: Utrecht, The Netherlands, 2010.

14. Mallet, V.; Quélo, D.; Sportisse, B.; Ahmed de Biasi, M.; Debry, É.; Korsakissok, I.; Wu, L.; Roustan, Y.; Sartelet, K.; Tombette, M.; et al. Technical note: The air quality modeling system Polyphemus. Atmos. Chem. Phys. 2007, 7, 5479-5487.

15. Roustan, Y.; Bocquet, M.; Musson, G.L.; Sportisse, B. Modeling Atmospheric Mercury at European Scale with the Chemistry Transport Model Polair 3D; National Environmental Research Institute: Copenhagen, Denmark, 2005.

16. Zhang, L.; Brook, J.R.; Vet, R. A revised parameterization for gaseous dry deposition in air-quality models. Atmos. Chem. Phys. 2003, 3, 2067-2082.

17. Zhang, L.; Wright, L.P.; Blanchard, P. A review of current knowledge concerning dry deposition of atmospheric mercury. Atmos. Environ. 2009, 43, 5853-5864.

18. Zhang, L.; Gong, S.; Padro, J.; Barrie, L. A size-segregated particle dry deposition scheme for an atmospheric aerosol module. Atmos. Environ. 2001, 35, 549-560.

19. Binkowski, F.S.; Roselle, S.J. Models-3 Community Multiscale Air Quality (CMAQ) model aerosol component 1. Model description. J. Geophys. Res.: Atmos. 2003, 108, AAC 3:1-3:18. 
20. Sportisse, B.; du Bois, L. Numerical and theoretical investigation of a simplified model for the parameterization of below-cloud scavenging by falling raindrops. Atmos. Environ. 2002, 36, 5719-5727.

21. Seinfeld, J.H.; Pandis, S.N. Atmospheric Chemistry and Physics: from Air Pollution to Climate Change; John Wiley \& Sons: New York, NY, USA, 2012.

22. Zyśk, J.; Wyrwa, A.; Pluta, M.; Roustan, Y.; Rafaj, P.; Kuenen, J.; Drebszok, K. Modelling of Atmospheric Dispersion of Mercury for Energy Scenarios of the EnerGEO Project; In Mercury in the environment - identification of hazards to human health; Falkowska, L. (Ed.); Uniwersytet Gdański: Gdańsk, Poland, 2013.

23. Zyśk, J. Modelling of Transport of Mercury in the Atmosphere. In Proceedings of the VII National Scientific Conference "Energy-Environment-Ethics”, Krakow, Poland, 2013.

24. CEC. A Roadmap for Moving to a Competitive Low Carbon Economy in 2050; Commission of the Europan Communities: Brussels, Belgium, 2011.

25. Russ, P.; Ciscar, J.-C.; Saveyn, B.; Soria, A.; Szabo, L.; Van Ierland, T.; Van Regemorter, D.; Virdis, R. Economic Assessment of Post-2012 Global Climate Policies; Joint Research Centre of the European Community: Seville, Spain, 2009.

26. UNEP. Global Mercury Cell Production Data; Global Mercury Partnership Advisory Group; United Nations Environment Programme: New York, NY, USA, 2010.

27. USGS. 2010 Minerals Yearbook-Gold; Mineral Commodity Summaries; US Geological Survey: Reston, VA, USA, 2012.

28. CremSoc. International Cremation Statistics 2010; The Cremation Society of Great Britain: Kent, UK, 2010.

29. Amann, M.; Borken-Kleefeld, J.; Cofala, J.; Heyes, C.; Klimont, Z.; Rafaj, P.; Purohit, P.; Schoepp, W.; Winiwarter, W. Future Emissions of Air Pollutants in Europe-Current Legistation Baseline and the Scope for Futher Reductions. TSAP Report \#1; International Institute for Applied Systems Analysis: Luxemburg, Austria, 2012.

(C) 2014 by the authors; licensee MDPI, Basel, Switzerland. This article is an open access article distributed under the terms and conditions of the Creative Commons Attribution license (http://creativecommons.org/licenses/by/3.0/). 